Review Article

\title{
Seasonal and Regional Variability of Long-Wave Effective Radiation in China and Associated Modulating Factors
}

\author{
Qianrong Ma, ${ }^{1}$ Jie Zhang $\mathbb{D}^{1},{ }^{1} \mathrm{Yu} \mathrm{Gu}^{2}{ }^{2}$ Yujun $\mathrm{Ma}^{3}$ and $\mathrm{Yu} \mathrm{Cao}{ }^{4}$ \\ ${ }^{1}$ Key Laboratory of Meteorological Disaster, Ministry of Education (KLME), \\ Joint International Research Laboratory of Climate and Environmental Change (ILCEC), \\ Collaborative Innovation Center on Forecast and Evaluation of Meteorological Disasters (CIC-FEMD), \\ Earth System Modeling Center, Nanjing University of Information Science and Technology (NUIST), Nanjing 210044, China \\ ${ }^{2}$ Jiangsu Yangzhou Meteorological Bureau, Yangzhou 225009, China \\ ${ }^{3}$ Key Laboratory of Mechanics on Disaster and Environment in Western China Ministry of Education, Lanzhou University, \\ Lanzhou 730000, China \\ ${ }^{4}$ Jiangxi Meteorological Service Center, Nanchang 33096, China
}

Correspondence should be addressed to Jie Zhang; gs-zhangjie@163.com

Received 30 January 2020; Revised 2 June 2020; Accepted 9 June 2020; Published 21 July 2020

Academic Editor: Hiroyuki Hashiguchi

Copyright (C) 2020 Qianrong Ma et al. This is an open access article distributed under the Creative Commons Attribution License, which permits unrestricted use, distribution, and reproduction in any medium, provided the original work is properly cited.

\begin{abstract}
Variations in all-sky and clear-sky long-wave effective radiation (LER) in China during the period 2001-2016 were determined using monthly radiative datasets from the Clouds and the Earth's Radiant Energy System (CERES). Annual and seasonal spatial distributions are found to be quite similar and show a decreasing trend from northwest to southeast, although highest values are found in spring. Mean LER under clear-sky conditions is approximately $20-30 \mathrm{Wm}^{-2}$ higher than that under all-sky conditions. There is a consistent downward trend in annual and seasonal variations of LER under different weather conditions in China especially after 2007. In northwest China, the eastern Tibetan Plateau, and southeast and northeast China, LER is significantly reduced in two weather conditions and this is more pronounced in spring. However, decreases in clear-sky LER are more obvious. Empirical orthogonal function (EOF) results for LER differences between all-sky conditions and clear-sky conditions were used to analyze regional characteristics and modulating factors. The first mode shows that the LER differences of two weather conditions over China become larger and significant after 2007. The second mode reflects the spatial characteristics, and four climate regions are divided according to the second pattern. According to the definition of LER, regression analysis shows that downward longwave radiation has a greater influence on LER. When considering cloud effects and other modulating factors, LER has higher correlation with relative humidity in climate regions 3 and 4 . However, there are higher negative correlations with middle and high clouds in regions 1 and 2, which are modulated by cloud characteristics. When these factors influence LER together, their correlation is significant in all regions (correlation coefficients are on average higher than 0.7). In summary, changes of LER can well reflect the change of climate system.
\end{abstract}

\section{Introduction}

The climate and radiation budget are intimately related, and radiative forcing acts as an important regulator of the atmospheric and climate system $[1,2]$. Solar radiation is absorbed and stored at the Earth's surface [3]. But the energy sink lost to the atmosphere is closely related to surface longwave radiation processes [4]. A detailed understanding of surface long-wave radiation processes is thus required to gain a more comprehensive understanding of the climate system [5].

Scientific research and observations of the long-wave radiation have mainly focused on upwelling outgoing longwave radiation (OLR) and the upwelling and downward long-wave radiation. It is generally believed that surface temperature and emissivity can be used to accurately calculate the amount of upwelling long-wave radiation (ULR) emitted by the surface. The downward long-wave radiation 
(DLR) is significantly correlated with air temperature, specific humidity, and cloudiness. The most variability in DLR can be explained by variations of specific humidity and cloud $[4,6]$. Long-wave radiation is generally regarded as a crucial parameter that links amounts of water vapor with surface warming $[7,8]$. Accurate and continuous observations of OLR can provide useful evidence for monitoring changes in the climate system. For example, changes in OLR can represent responses to recent increases in well-mixed greenhouse gases and thus provide a measure of how greenhouse gases affect the Earth system [9-12]. However, to make proficient estimations of climate change, it is necessary to highlight more factors operating within the surface longwave radiation process.

Long-wave effective radiation (LER) is based on observed ULR and DLR and adopts the expression LER = ULRDLR to describe, which is also known as the net surface longwave radiation flux [13]. It is thus generally believed that evaluating the characteristics of LER would be useful to gain a comprehensive understanding of the effects of different weather factors on the radiation process. As the atmosphere provides thermal radiation, LER is also known as the net flux of surface long-wave radiation. LER is consistent with ULR radiation changes; these differ from DLR and show significant seasonal and regional characteristics $[13,14]$. Changes in surface temperature, cloud, atmospheric temperature, and water vapor also correspondingly influence LER [15]. LER also acts as an important component of surface net radiation, which may affect evaporation, heating of soil and air, and development of the planetary boundary layer [16]. And most of the models $[17,18]$ need input exact assessment of radiation flux. Therefore, LER quantification is crucial to determine changes occurring over the surface and for studying land-atmosphere interactions and improving model simulation accuracy.

With advancements made in remote sensing in recent years, high spatial-resolution and long temporal-resolution satellite observation data have been available for use in mapping large-scale radiation processes. Various satellite data such as Geostationary Operational Environmental Satellites (GOES), Advanced Very High Resolution Radiometer (AVHRR), and Moderate Resolution Imaging Spectroradiometer (MODIS) have successfully been utilized to estimate radiation flux [19-21]. In addition, satellite remote sensing is one of the most important methods used to estimate LER on regional and global scales. The NASA Clouds and the Earth's Radiant Energy System (CERES) mission is dedicated to observing the top of atmosphere (TOA) global energy budget and is used for estimating surface and within atmosphere radiation budgets [22-24]. Terra (launched in 1999) and Aqua (launched in 2002) are two CERES instrument sets that are in sun-synchronous orbits and have equator crossing times of 1030 and 1330 local time. The CERES instrument has been in operation since March 2000, and it has provided over a decade of TOA global energy budget data that are critical for use in cloud and radiation studies. CERES-observed cloud and radiative factors are provided with a Synoptic 1 degree (SYN1deg) Ed3A $1^{\circ}$ latitude $\times 1{ }^{\circ}$ longitude gridded data product (http:// ceres.larc.nasa.gov). The current CERES level 3 data product provides observed TOA broadband reflected short and longwave radiation fluxes, which are consistent with the associated MODIS-derived results [25]. Many other global products have used satellite data to estimate surface radiation, such as the Global Energy and Water cycle Experiment-Surface Radiation Budget (GEWEX-SRB) and the International Satellite Cloud Climate Project (ISCCP), which also provides cloud and radiation products [26]. However, the evaluation of satellite-estimated long-wave radiation found in CERES data is more accurate than that related to GEWEX and ISCCP [27]. Therefore, in this study, CERES-observed Chinese cloud and radiative factors provided by SYN1deg data products are utilized and analyzed for the period 2001 to 2016.

In order to quantify more accurate radiative process, estimation of LER is vital. The first objective of this study is therefore to obtain regional and seasonal distribution of LER by CERES data. Secondly, we explore the potential relationships between LER and climate factors in different seasons and regions. Section 2 describes the datasets and methods. Section 3 exhibits the climatological characteristics of LER under all-sky and clear-sky conditions. Section 4 outlines factors modulating LER, and Section 5 provides summary and discussion.

\section{Data and Method}

2.1. Data. The main objective of the NASA CERES project is to understand the relationship between clouds and radiation processes. In this paper, we apply the level 3 monthly surface long-wave radiative fluxes from CERES provided by both Terra and Aqua under two different weather conditions (allsky and clear-sky). Clear-sky region is defined as a region whose cloud cover fraction is lower than $1 \%$ [28]. The $1.0^{\circ} \times$ $1.0^{\circ}$ gridded surface DLR and ULR are provided in SYN1deg Ed3A data. CERES surface fluxes are calculated using a radiative transfer model provided by the Global Modeling and Assimilation Office and MODIS-derived cloud and aerosol properties [23, 29]; these calculations are then constrained and fixed by observed TOA outgoing fluxes [30].

CERES cloud properties are acquired from a Visible Infrared Scanner (VIRS) and MODIS instruments and include cloud fraction, cloud phase, temperature, height, optical depth, effective particle size, and water path [31]. The CERES cloud products analyzed here consist of $1.0^{\circ} \times 1.0^{\circ}$ cloud fractions at different heights, which are computed from CERES Terra Edition2B and Aqua Edition1A 1kmpixel-level results. According to CERES observation methods, clouds are divided into different types by their height as equivalent pressure $(P)$ : low cloud cover $(P \geq 700 \mathrm{hPa}$ LCC $)$; middle cloud cover (700 hPa $\geq P>300 \mathrm{hPa}, \mathrm{MCC})$, and high-level cloud cover $(P \geq 300 \mathrm{hPa}, \mathrm{HCC})$ [32]. The entire observation period in China from 2001 to 2006 is analyzed in this study. CERES products and associated documentation can be obtained at the project website (http://ceres.larc.nasa.gov). 
ERA-Interim reanalysis provided by the European Center for Medium-Range Weather Forecasts (ECMWF) global assimilation scheme is used to research influencing factors [33]. The selected variables are relative humidity $(\mathrm{RH})$, air temperature (Ta), and surface and geopotential height; atmospheric data are available on a $1.0^{\circ} \times 1.0^{\circ}$ grid on 37 pressure levels from $1000 \mathrm{hPa}$ to $1 \mathrm{hPa}$. The main advantages of using ERA-Interim reanalysis data assimilation are that it provides $4 \mathrm{D}$ variational analysis on a spectral grid with triangular truncation of 255 waves (corresponds to approximately $80 \mathrm{~km}$ ) and hybrid vertical coordinates [34]. The ERA-Interim period covers from 1979 to the present day, but ERA-Interim data used in this study relate to the period 2001-2016 over China.

\subsection{Methods}

2.2.1. The Empirical Orthogonal Function (EOF) Analysis. Empirical orthogonal function (EOF) analysis which is widely used in climate research is employed to obtain the leading modes of LER. The EOF analysis is a decomposition of a variable in terms of orthogonal basis functions determined by the variable characteristics $[35,36]$. The EOF method has been improved a lot from the principal component analysis; it can exhibit both time series and spatial patterns of the variable. EOF analysis reduces the dimensionality of a complex variable into linear combinations and represents the maximum possible fraction of the variance contained in the original data [37]. Here, we use EOF analysis in China constructing an area-weighted covariance matrix of the LER for the period 2001-2016. Meanwhile, the North test [38] is employed to examine whether the principal components are statistically significant.

Hence, we use EOF analysis in China constructing an area-weighted covariance matrix of the LER for 2001-2016. And the first three patterns can be depart from other modes according to the North test and nearly 33\% of the total domain variance. The results are then used to isolate the study field and to obtain spatial divisions and to identify the variance of the squared correlation coefficient between the time series and the EOF modes. In addition, the standardized PCs show the temporal characteristics for LER. They cause the spatial modes to be easier to interpret and enable the definition of regional spatial structures.

2.2.2. Statistical Methods. Ordinary least squares fits are calculated to determine the linear trends of the variables and the significance is tested using a student's $t$-test. The statistically significant level is $5 \%$. The annual mean time series of climate factors in China were calculated based on the areaweighted average within grid boxes of $1.0^{\circ} \times 1.0^{\circ}$. Correlation coefficients between regional LER and air temperature, relative humidity, and different level clouds are analyzed where significance level of Spearman's correlation coefficients exceeding $95 \%$ is used [19].

To analyze relationships between LER and multiple dependent variables, linear regression and multivariate regression have been used to select impact factors and establish the statistical correlation model. The multivariate regression could explain the best combination of the LER and predictor variables [39]. The predictor variables are statistically continuously entered into the regression equation only if additional variables add anything statistically to the regression equation, and the statistical correlation model between LER and predictor variables is established.

\section{Climatological Characteristics of LER}

The variation of LER is closely related to surface and atmospheric properties, water vapor, and cloud cover [40]. In order to assess the fiddly LER, it is important to understand the variability of the different weather conditions properties.

The annual and seasonal LER spatial distribution characteristics under all-sky conditions are shown in Figure 1. From annual and seasonal time scale, LER shows evident decreasing trends from northwest to southeast. In the Tibetan Plateau and northwestern hinterland, higher elevation and lower water vapor contribute to less DLR and more LER. In contrast, the adequate water vapor and larger amount of cloud cover in the southeast region contribute to strengthening DLR and leading to a reduction in LER. Annual all-sky LER shown in Figure 1(a) indicates that the higher values are accompanied with less water vapor. In previous research studies, with the influence of the "stack effect" from the upper atmosphere and local cloud effects, LER is lower on the southern and southeastern Tibetan Plateau than in other high elevation regions [13, 41].

In different seasons, the all-sky LER shows the largest values in spring (with a regional average value of $72 \mathrm{Wm}^{-2}$ ) followed by summer $\left(66 \mathrm{Wm}^{-2}\right)$ and then winter $\left(64 \mathrm{Wm}^{-2}\right)$, and the absolute lowest value is in autumn $\left(58 \mathrm{Wm}^{-2}\right)$. In spring, with the increase of temperature, the ULR drastically increases and contributes to more LER. In summer, frequent precipitation and higher relative humidity will enhance DLR which weakens the LER. More clear-sky weather occurs in autumn and more solar radiation heats the ground. Meanwhile, the atmospheric temperature increases and induces more atmospheric inverse radiation, which leads to the less LER. The lowest ground surface temperature leads to the decrease of ULR and LER. All-sky conditions are usually associated with the "greenhouse effect" according to cloud impact on atmospheric inverse radiation [13, 42]. Thus, more investigations are needed for LER to get more comprehensive study of the "greenhouse effect" and other cloud radiation effects.

Considering the effect of clouds on the radiation budget, Figure 2 presents an analysis of LER under clear-sky conditions. The spatial distribution characteristics from annual and seasonal time scale are similar to those under all-sky conditions. Obvious gradients are exhibited from the northwest to southeast. In addition, regional averaged values are $20-30 \mathrm{Wm}^{-2}$ higher than those for all-sky conditions mainly due to cloud absorption of DLR and simultaneous emission of long-wave radiation on the surface, which leads to an increase in DLR. This mechanism explains the lower all-sky LER values compared to clear-sky conditions [42, 43]. Similarly, the highest values of clear-sky condition LER 


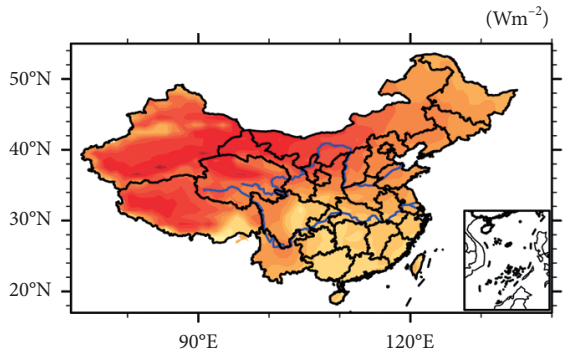

$20 \quad 30 \quad 40 \quad 5060 \quad 70 \quad 80 \quad 90 \quad 100110120130140150$

(a)

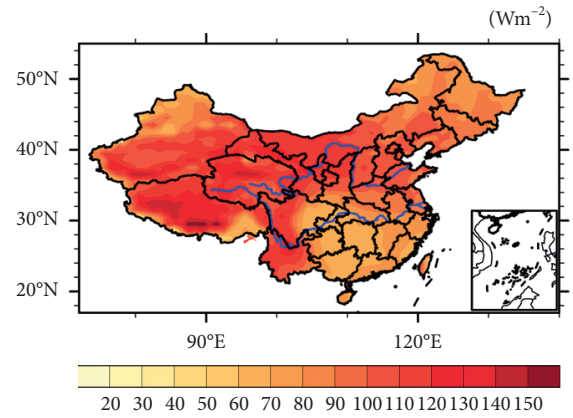

(b)

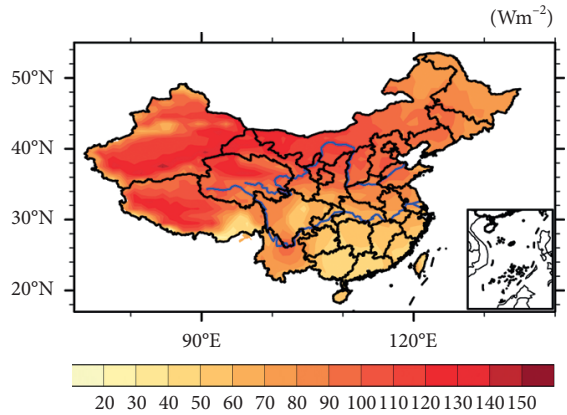

(c)

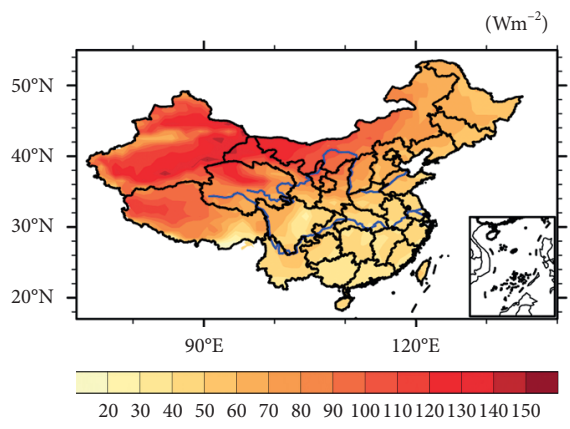

(d)

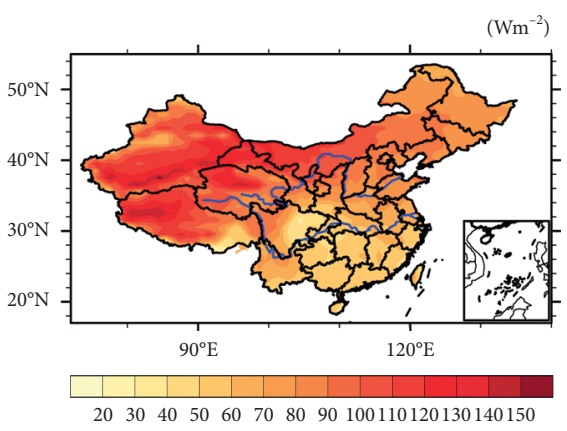

(e)

FIGURE 1: Distribution of annual and seasonal LER mean (unit: $\mathrm{Wm}^{-2}$ ) in China under all-sky conditions during the period 2001-2016: (a) annual, (b) spring, (c) summer, (d) autumn, and (e) winter.

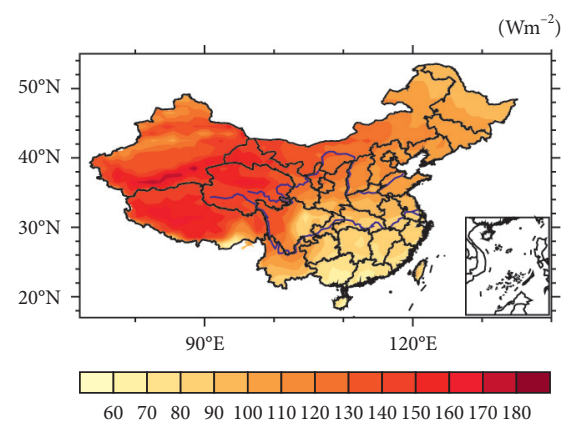

(a)

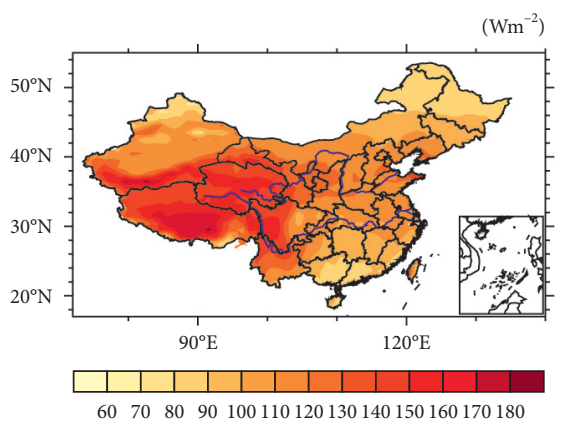

(b)

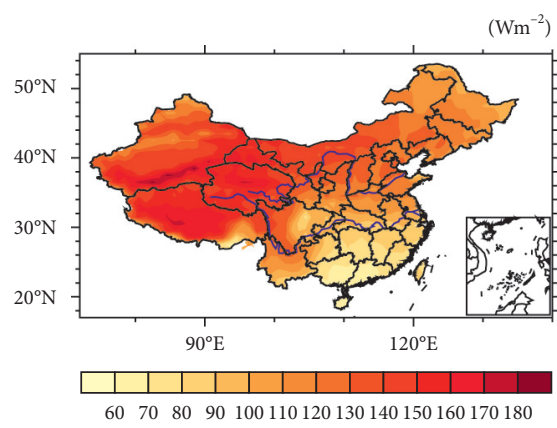

(c)

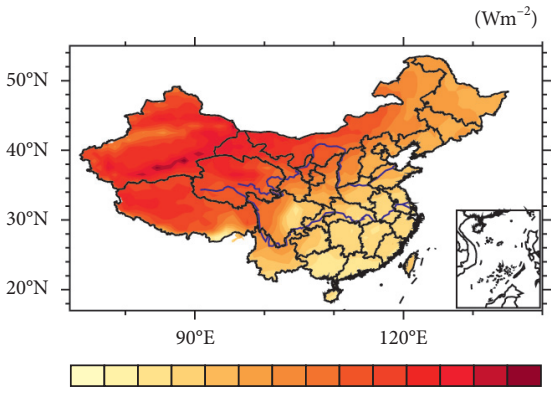

$60 \quad 70 \quad 80 \quad 90100110120130140150160170180$

(d)

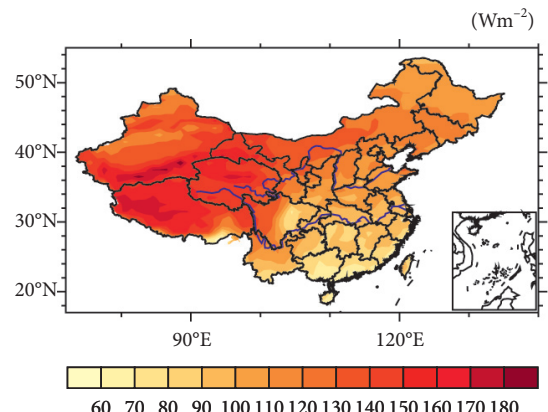

(e)

FIGURE 2: Distribution of annual and seasonal LER mean (unit: $\mathrm{Wm}^{-2}$ ) in China under clear-sky conditions during the period 2001-2016: (a) annual, (b) spring, (c) summer, (d) autumn, and (e) winter. 
occur in spring (about $97 \mathrm{Wm}^{-2}$ ), and other seasons show less variation (the average value is approximately $85 \mathrm{Wm}^{-2}$ ). It is worth mentioning that clear-sky LER in the northern part of the plateau has a lower value than all-sky LER which is presumably related to the influence of surface albedo adjusted by snow cover and so on.

Subsequently, we investigate the LER variations under different sky conditions. Firstly Figure 3 shows the spatial distribution of linear trends of annual and seasonal LER under all-sky conditions. As a whole, evident decreasing trends of all-sky LER under all-sky conditions have been exhibited during the study period in China, particularly in northern Xinjiang province, northern and eastern parts of the Tibetan Plateau, and eastern coastal areas. In Figure 3(a), slight increasing trends are found over the western Tibetan Plateau and southern Xinjiang province from annual scale. With respect to seasonal variations, changes of LER in allsky conditions show obvious seasonal and regional characteristics. In spring, significant decreasing trends of LER are observed over the northern and eastern Tibetan Plateau, northern Xinjiang province, and northeastern China and increasing trends are observed in northern and southern China. In summer and autumn, similar significant decreases have been found in most areas in China and mild increases have been found in western Tibetan Plateau (in Figures 3(c) and 3(d)). Besides, the LER in all-sky conditions in winter shown in Figure 3(e) indicates significant decreases in northern and eastern Tibetan Plateau and eastern coastal areas. In southern Xinjiang province and northern and northeastern China, increasing trends occurred.

In Figure 4, spatial distribution of linear trends of LER under clear-sky conditions is discussed. Evidently, both the annual and seasonal changes are generally consistent with the results of all-sky conditions, but decreasing trends are more pronounced. The most significant decreasing changes are seen particularly in the northern Xinjiang province, northeast China, east Tibetan Plateau, and eastern coastal areas of China in annual, spring, summer, and autumn time. The decreasing trend reaches- $5 \mathrm{Wm}^{-2} /$ year (in Figure 4(a)). Seasonal variations are similar to the LER in all-sky conditions. In recent years, more soil moisture, precipitation, water vapor content, and increasing atmosphere temperature in northern Xinjiang province and east Tibetan Plateau can result in the LER changes. In addition, in northeastern and eastern coastal areas of China, clouds are more outstanding for the LER [44].

Finally, the regional averaged time series of annual and seasonal LER in China for all-sky conditions and clear-sky conditions during the period 2001-2016 are discussed. The pick values of the LER under different weather conditions are seen in spring. In spring, the ULR drastically increases with the increase in surface temperature, and the increase amplitude is much larger than DLR, which leads to higher LER. In summer, frequent precipitation and high humidity lead higher DLR and weaker LER. Cloud cover reduces in autumn and more solar radiation reaches the ground, which simultaneously increases the ULR and DLR. AS a result, the LER shows smaller variability than in summer. However, the surface temperature drops rapidly in winter, which accompanies with the ULR, and the LER decreases. LER in allsky conditions in summer and autumn is significantly reduced $\left(-0.41\right.$ and $-0.40 \mathrm{Wm}^{-2} /$ year, respectively) in Figure 5(a). Clear-sky LER also shows significantly decreasing trends in spring, summer, autumn, and annual time scale $\left(-0.41,-0.57,-0.54\right.$, and $-0.47, \mathrm{Wm}^{-2} /$ year, respectively) in Figure 5(b). Trend coefficients are at 95\% significance level. In addition, the winter LER in all-sky condition is smaller than that in clear-sky conditions. It is mainly due to the "greenhouse effect" of the atmosphere we discussed before.

\section{Factors Modulating LER}

The LER represents the difference between the ULR and DLR. Therefore, we explore here how the LER reflects changes in ULR and DLR under different weather conditions.

Least squares regression was employed to determine the relationship between LER and ULR and DLR, and Figure 6 shows the slopes of annual and seasonal relationships under all-sky conditions. Although correlations show certain seasonal differences, LER is generally seen to have a positive correlation with ULR and a negative correlation with DLR. The absolute values of annual and seasonal (except winter) sensitivity of LER to DLR changes $(-0.67)$ are higher than those to ULR (0.33). In addition, the magnitude of summer sensitivity to DLR reaches -0.86 and a $95 \%$ significance level, whereas sensitivity is lower in magnitude in spring $(-0.65)$ than in autumn (-0.71). The approximation of linear relationships between LER and DLR in summer and autumn is 0.70 and 0.54 ; however, the linear relationship between LER and ULR does not appear to fit and there are low correlations in all seasons.

Figure 7 shows the annual and seasonal relationships between LER-C and ULR-C and DLR-C (LER-C, ULR-C, and DLR-C are radiation fluxes under clear-sky conditions). The absolute values of annual and seasonal sensitivity of LER-C to DLR-C and ULR-C are similar to those for all-sky conditions. However, the magnitudes of LER-C sensitivity to DLR-C in all seasons are larger than those for all-sky, and the magnitude of summer sensitivity to DLR-C reaches -0.92 , but sensitivity is slightly higher in spring than in autumn. The annual linear relationships between LER-C and DLR-C reach 0.63 at the $95 \%$ significance level. The effect of DLR-C on LER-C is therefore more significant, and there is a strong linear relationship between LER-C and DLR-C in summer and autumn ( 0.69 and 0.77 , respectively). LER-C is also less sensitive to changes in ULR-C.

These results show that LER may have a greater correspondence with changes in DLR. However, ULR acts as a function of net shortwave flux and shows thermal inertia [3], and cloud has a considerable influence on LER under certain weather conditions.

To enable further analysis of the cloud effect, Figure 8 shows differences between all-sky and clear-sky LER. Large differences are apparent over the Tibetan Plateau, where cloud cover causes significant changes in the corresponding period [45]. The differences between DLR and ULR under different weather conditions are also analyzed in Figures 9 


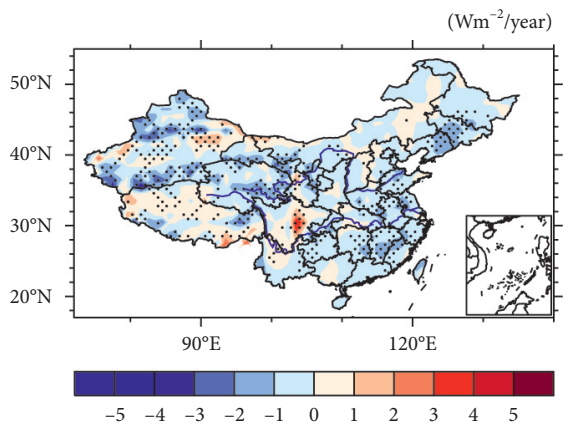

(a)

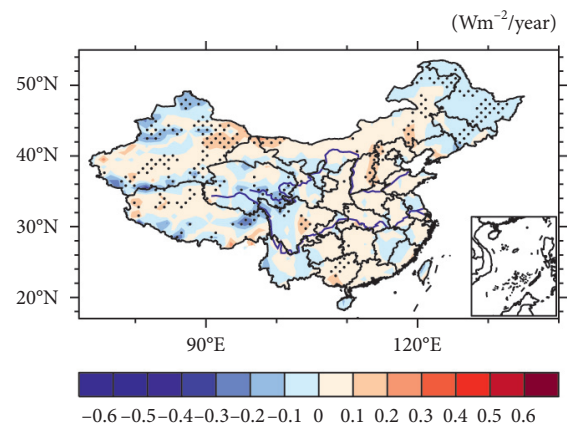

(b)

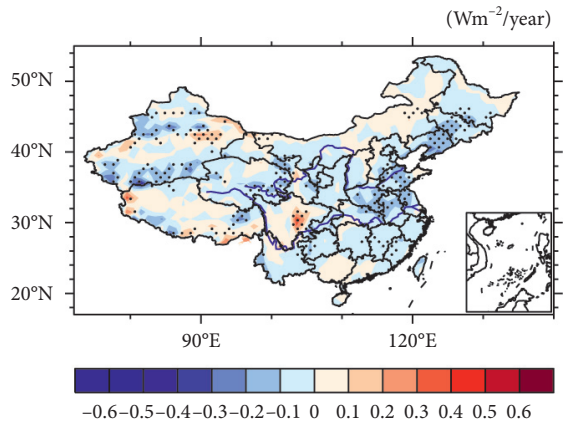

(c)

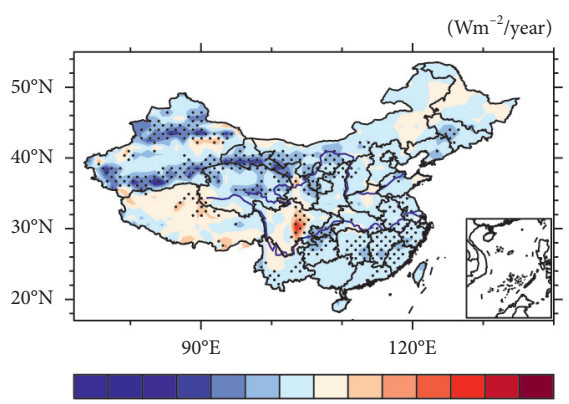

$\begin{array}{llllllll}-0.6-0.5-0.4-0.3-0.2-0.1 & 0 & 0.1 & 0.2 & 0.3 & 0.4 & 0.5 & 0.6\end{array}$

(d)

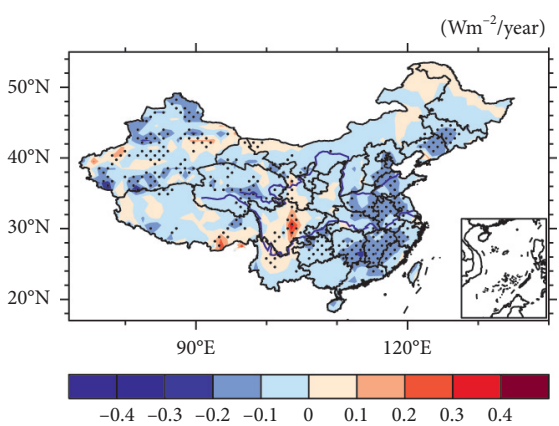

(e)

FIgURe 3: Distribution of annual and seasonal linear LER trends $\left(\mathrm{Wm}^{-2}\right)$ in China under all-sky conditions during 2001-2016 (dot regions indicate that linear trends attained the 95\% significance level): (a) annual, (b) spring, (c) summer, (d) autumn, and (e) winter.

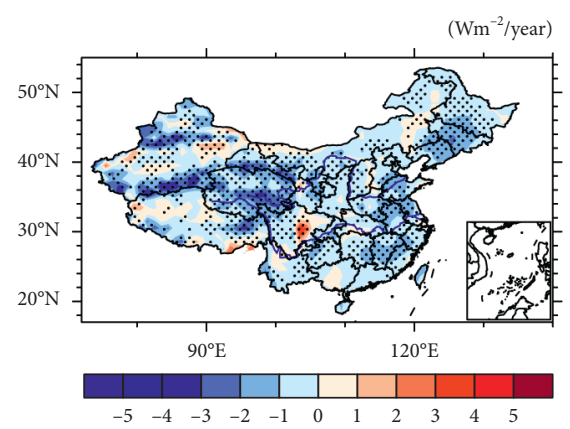

(a)

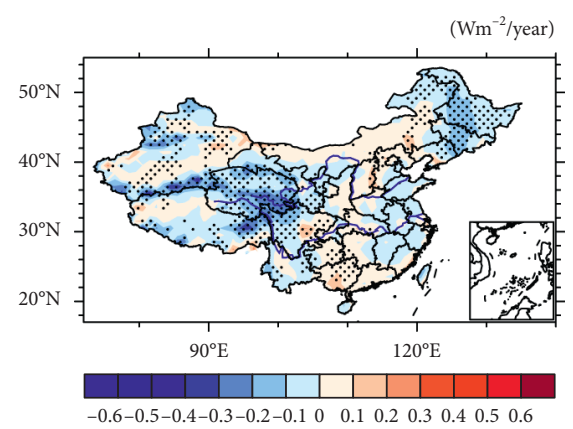

(b)

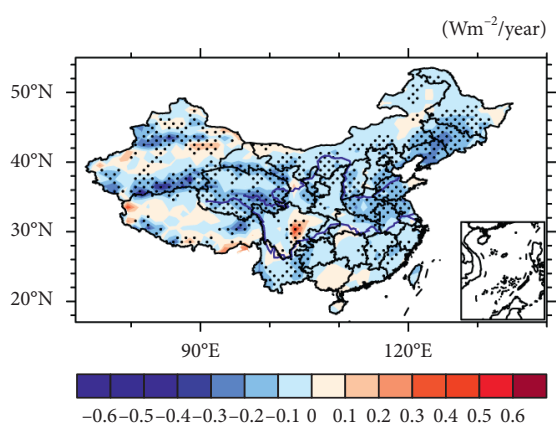

(c)

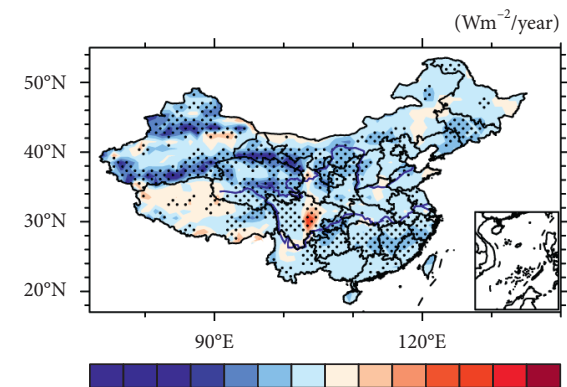

$-0.6-0.5-0.4-0.3-0.2-0.10 \quad 0.10 .20 .30 .40 .50 .6$

(d)

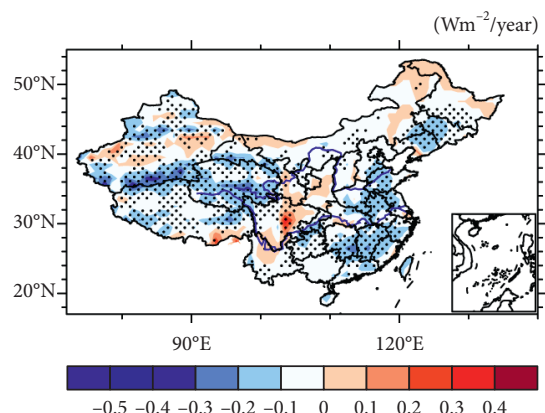

(e)

FIGURE 4: Distribution of annual and seasonal linear LER trends $\left(\mathrm{Wm}^{-2}\right)$ in China under clear-sky conditions during 2001-2016: (a) annual, (b) spring, (c) summer, (d) autumn, and (e) winter. 


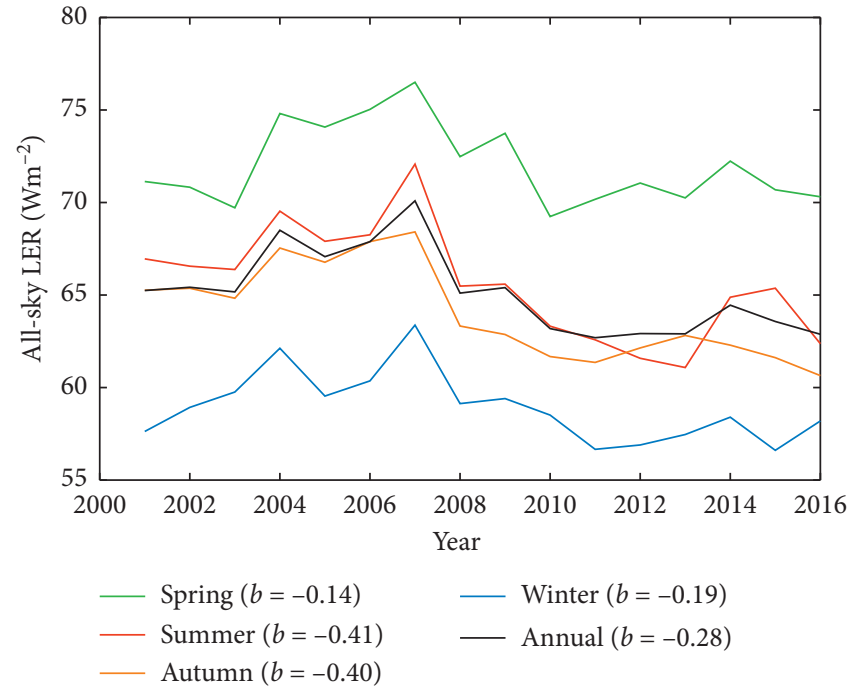

(a)

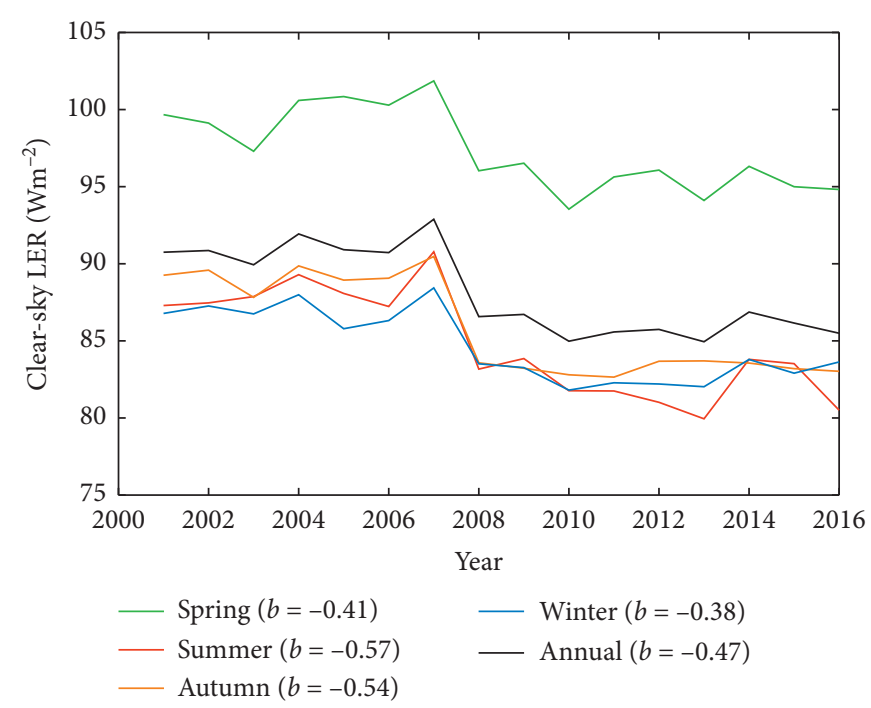

(b)

FIGURE 5: Time series of annual and seasonal LER $\left(\mathrm{Wm}^{-2}\right)$ in China for (a) all-sky conditions and (b) clear-sky conditions during the period 2001-2016.

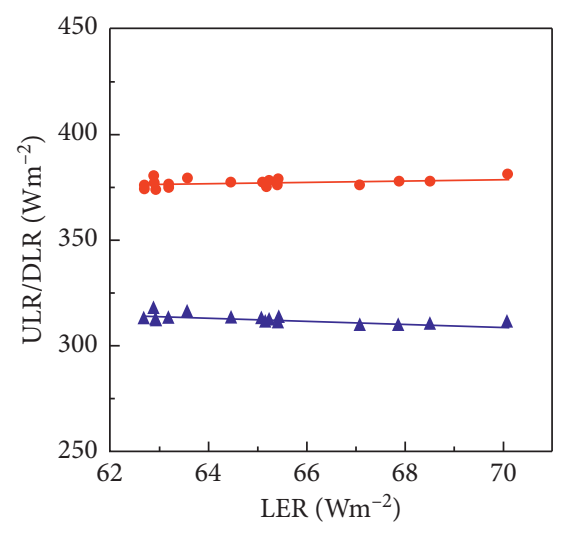

- ULR (0.33)

$\triangle \operatorname{DLR}(-0.67)^{*}$

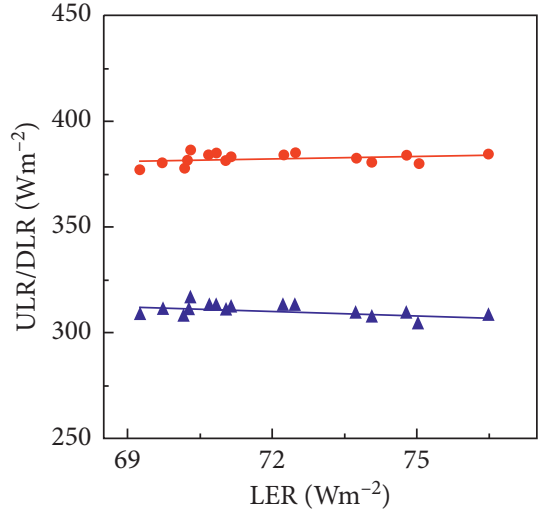

- $\operatorname{ULR}(0.34)$

\ $\operatorname{DLR}(-0.65)^{*}$

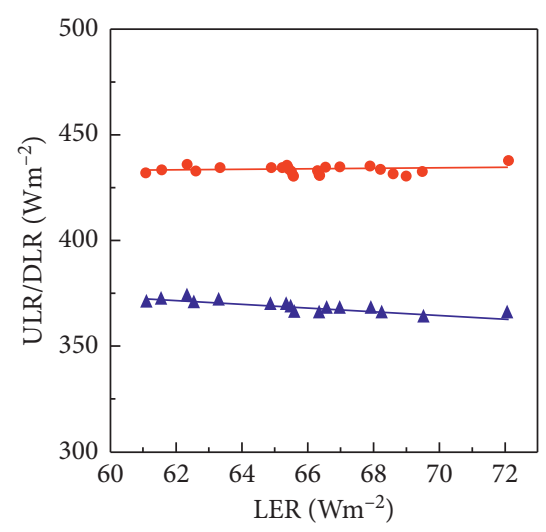

- ULR (0.14)

\ $\operatorname{DLR}(-0.86)^{*}$

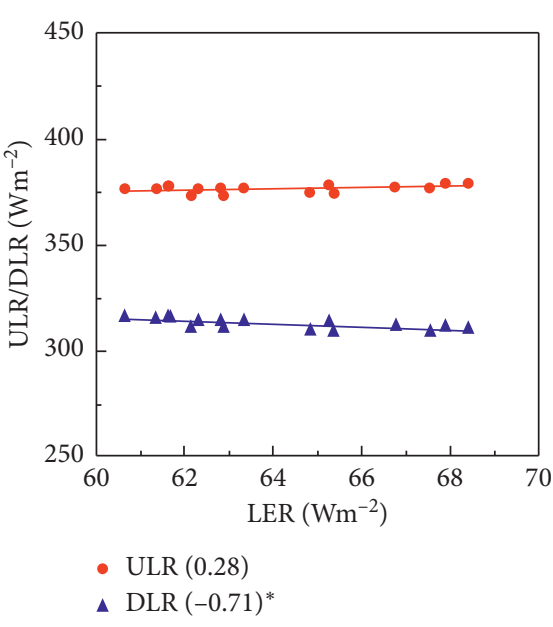

(d) (b)

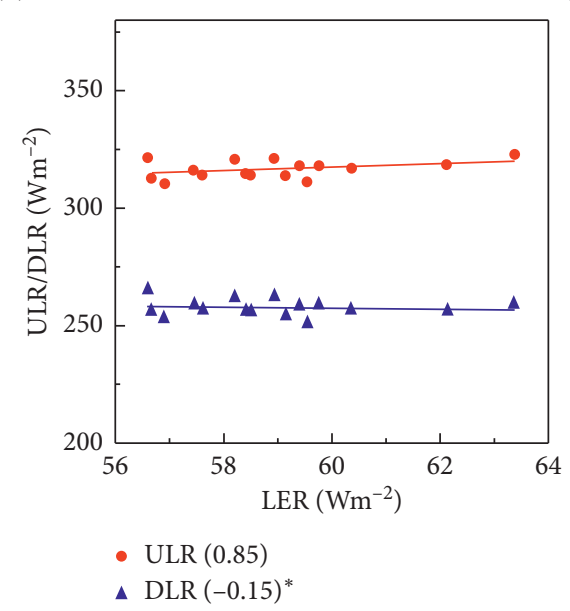

(e)

FIgURE 6: Slopes of (a) annual and (b-e) seasonal linear regressions for relationship between LER and ULR (red) and DLR (blue) (unit: $\mathrm{Wm}^{-2}$ ) under all-sky conditions in China during the period 2001-2016 (asterisk indicates 95\% significance level). 


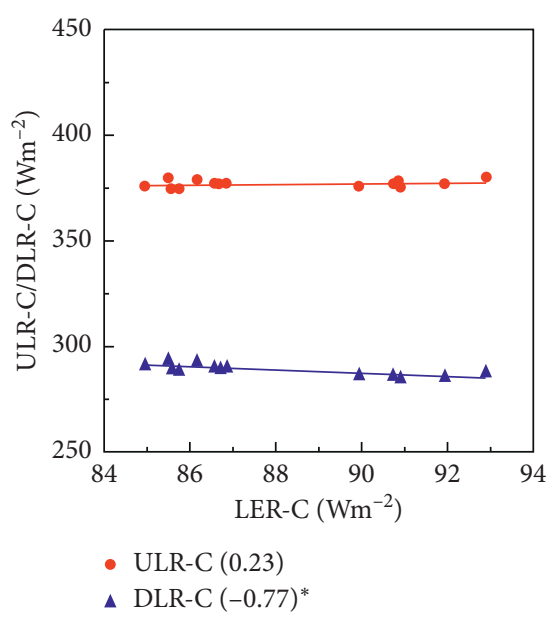

(a)

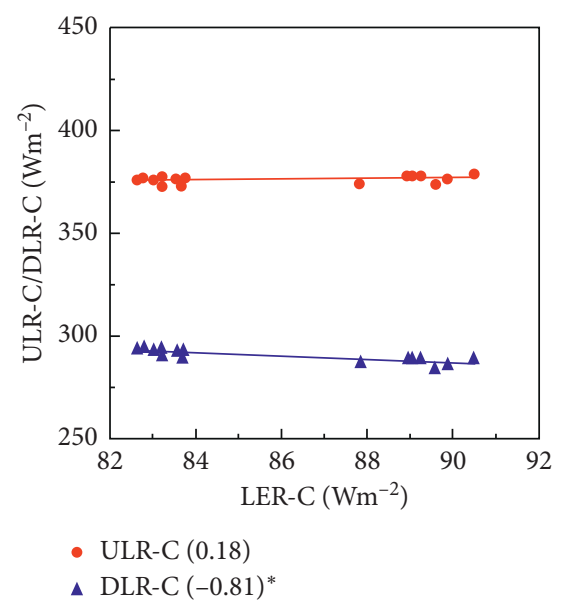

(d)

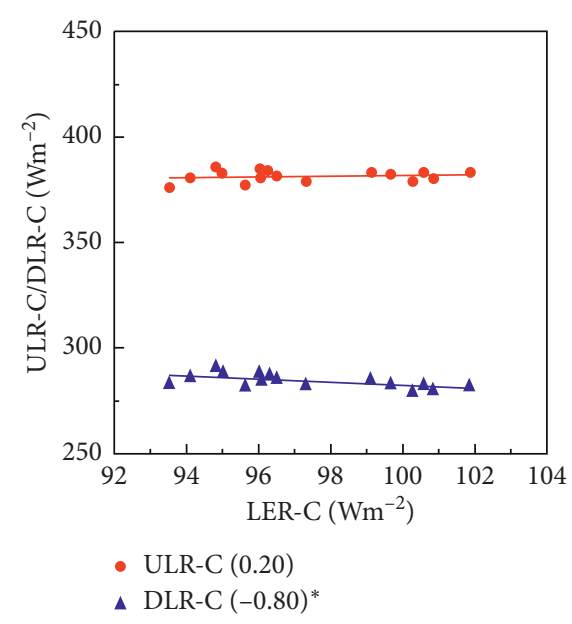

(b)

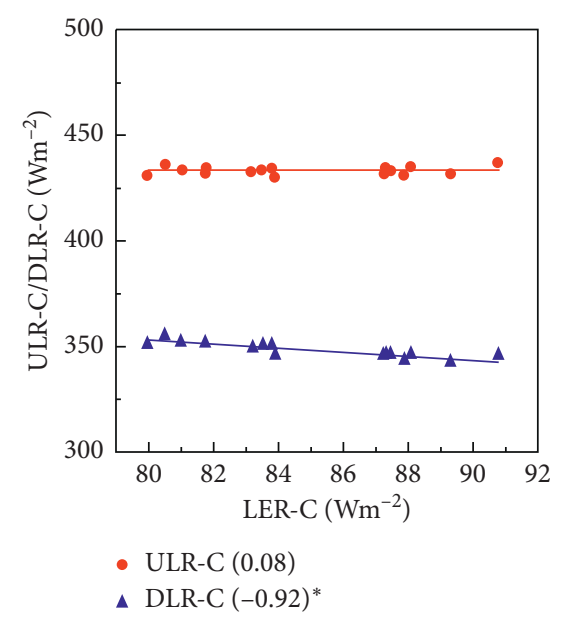

(c)

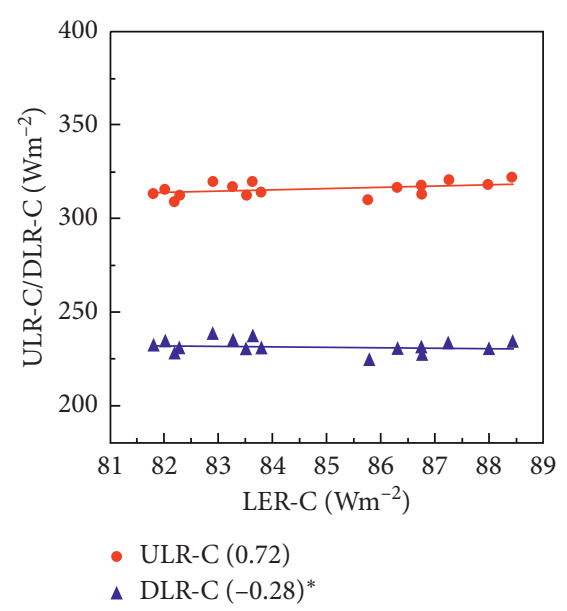

(e)

FIgURE 7: Slopes of annual and seasonal linear regressions for relationship between LER and ULR (red) and DLR (blue) under clear-sky conditions during the period 2001-2016 (LER-C, ULR-C, and DLR-C are radiation fluxes under clear-sky conditions): (a) annual, (b) spring, (c) summer, (d) autumn, and (e) winter.

and 10. However, there are small differences in ULR under different weather conditions. The difference of ULR under different weather conditions is much smaller than DLR. The difference of LER under different weather conditions is mainly caused by DLR, and the distribution features are similar Therefore, it can be seen that cloud mainly affects DLR and causes differences in LER and that there are obvious seasonal and regional differences.

According to Figures 3 and 4, LER shows significant seasonal and regional characteristics under different weather conditions. We have considered the significance of cloud effects on LER.

Therefore, to better understand the modulating factors of LER in China, an EOF analysis was conducted to confirm the difference of all-sky LER and clear-sky LER during the period 2001 to 2016, and results are shown in Figure 11. A combination of the spatial distribution of the first EOF mode and the corresponding time series shows an increasing trend in the difference of LER in the two kinds of weather conditions in China, and the variation is more obvious after 2007. The second EOF mode shows obvious regional characteristics: areas of reduction are centered in northwestern and central-eastern China, but there is an increasing trend on the Tibetan Plateau and northeastern China. With respect to the second mode time series, spatial variation characteristics are more significant after 2009. However, the third EOF mode presents a north-south antipodal phase.

To consider regional differences, Figure 12 shows the division of climate regions according to the spatial distribution characteristics of the second EOF mode: the first region is $38^{\circ} \mathrm{N}-49^{\circ} \mathrm{N}, 70^{\circ} \mathrm{E}-104^{\circ} \mathrm{E}$; the second region is $25^{\circ} \mathrm{N}-40^{\circ} \mathrm{N}, 70^{\circ} \mathrm{E}-104^{\circ} \mathrm{E}$; the third region is $20^{\circ} \mathrm{N}-45^{\circ} \mathrm{N}$, $104^{\circ} \mathrm{E}-122^{\circ} \mathrm{E}$; and the fourth region is $40^{\circ} \mathrm{N}-50^{\circ} \mathrm{N}$, $122^{\circ} \mathrm{E}-132^{\circ} \mathrm{E}$. Modulating factors of LER are thus discussed in detail through the partitioning of these results.

ULR is expressed by $U L R=\varepsilon_{0} \sigma T_{0}^{4}$, where $\varepsilon_{0}$ is surface emissivity, $s$ represents the Stefan-Boltzmann constant, and $T_{0}$ is the land surface temperature. DLR can be 


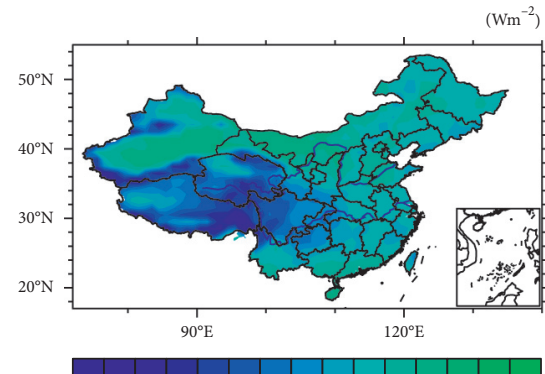

$-70-65-60-55-50-45-40-35-30-25-20-15-10-5$

(a)

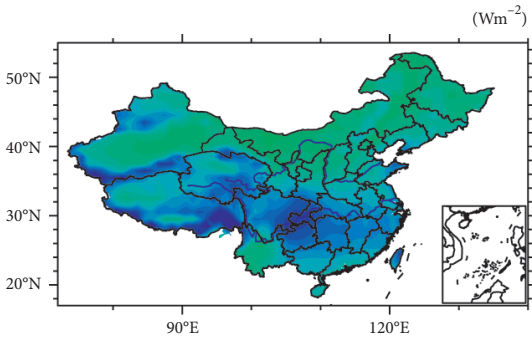

$-70-65-60-55-50-45-40-35-30-25-20-15-10-5$

(b)

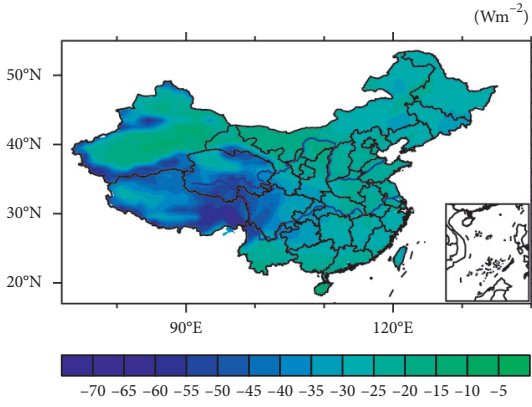

(c)

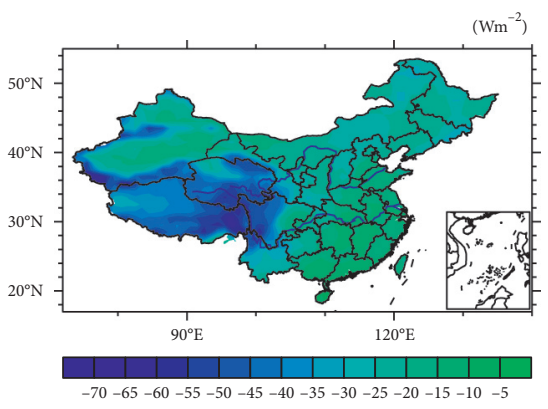

(d)

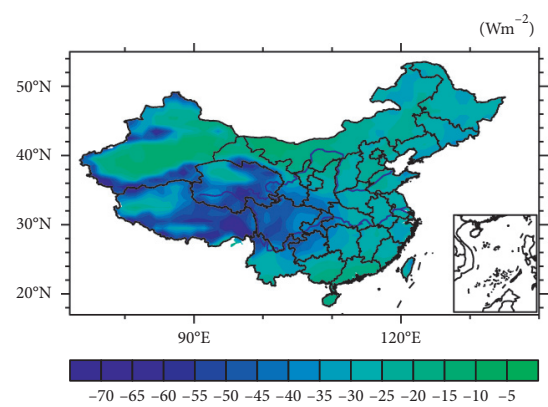

(e)

FIGURE 8: Differences in LER $\left(\mathrm{Wm}^{-2}\right.$ ) in China between all-sky conditions and clear-sky conditions during 2001-2016: (a) annual, (b) spring, (c) summer, (d) autumn, and (e) winter.

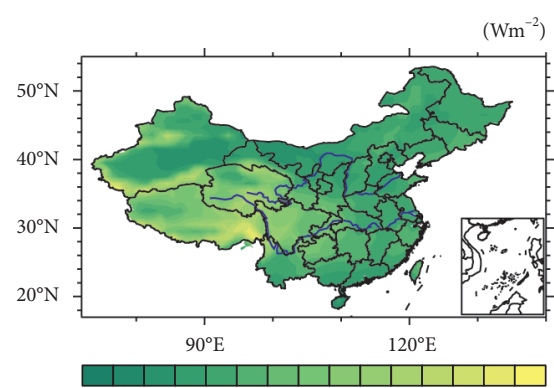

1015202530354045505560657075

(a)

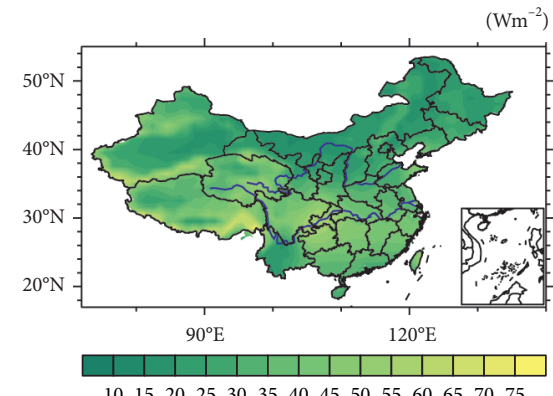

1015202530354045505560657075

(b)

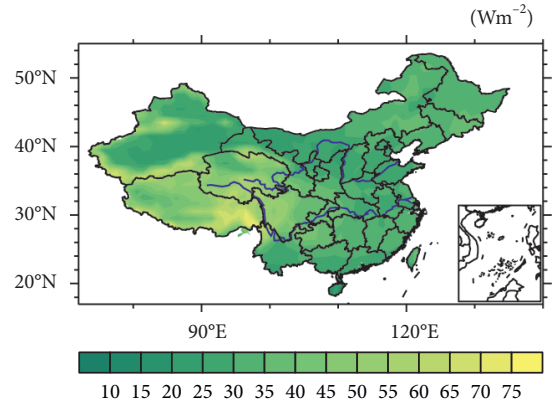

(c)

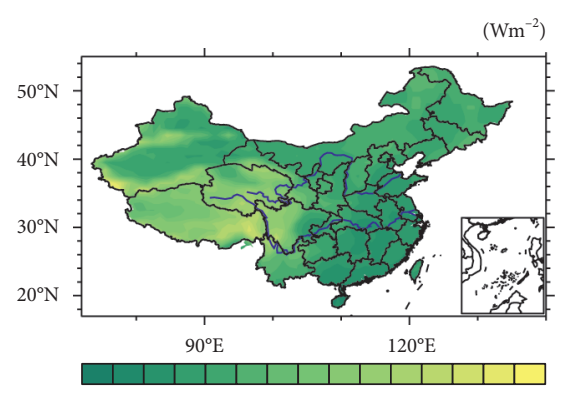

$\begin{array}{lllllllllllllll}10 & 15 & 20 & 25 & 30 & 35 & 40 & 45 & 50 & 55 & 60 & 65 & 70 & 75\end{array}$

(d)

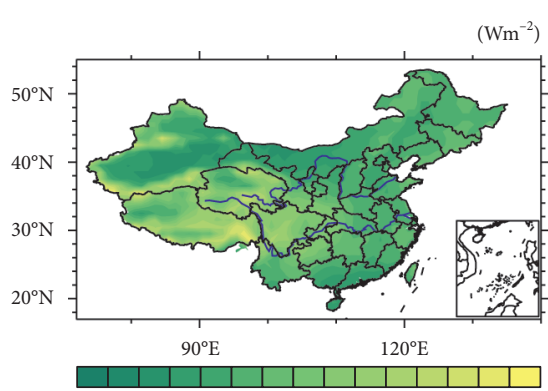

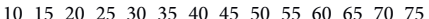

(e)

FIGURE 9: The difference of the DLR $\left(\mathrm{Wm}^{-2}\right)$ in China between the all-sky conditions and clear-sky conditions during 2001-2016: (a) annual, (b) spring, (c) summer, (d) autumn, and (e) winter. 


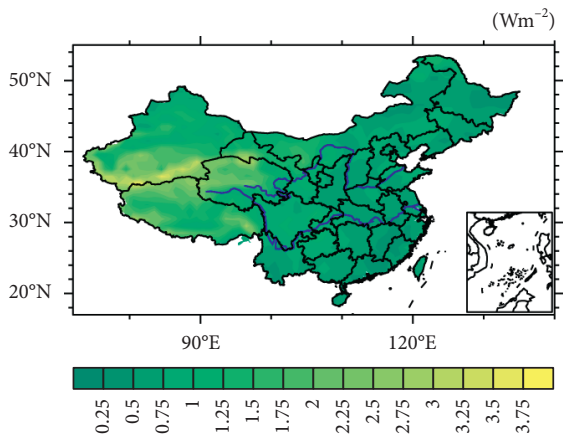

(a)

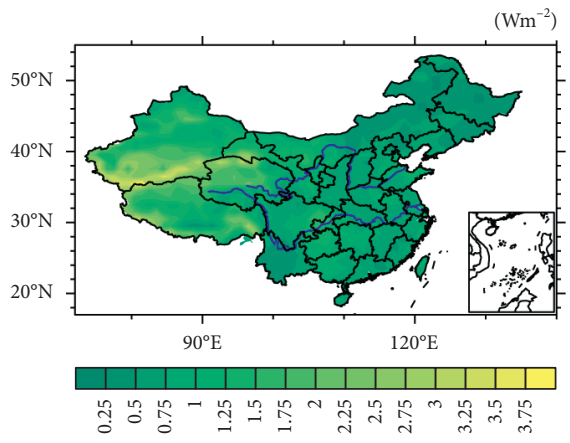

(b)

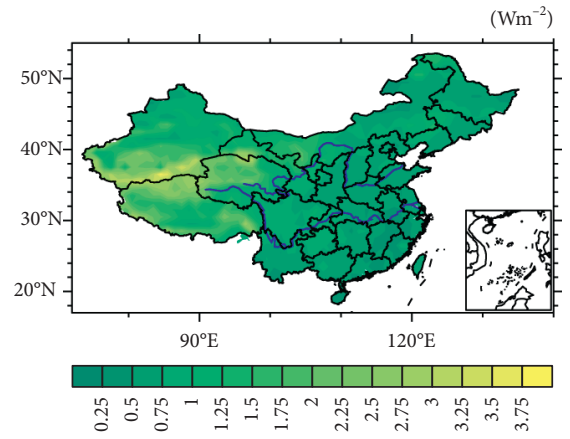

(c)

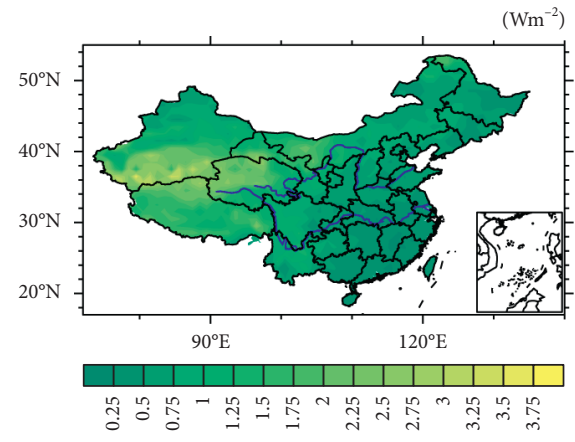

(d)

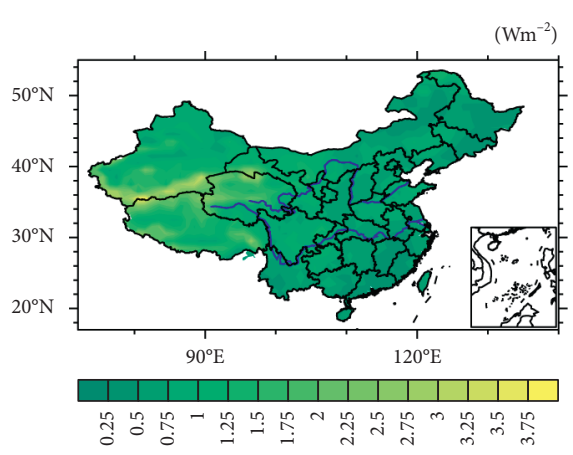

(e)

FIgURE 10: The difference of the ULR $\left(\mathrm{Wm}^{-2}\right)$ in China between the all-sky conditions and clear-sky conditions during 2001-2016: (a) annual, (b) spring, (c) summer, (d) autumn, and (e) winter.

calculated by $D L R=\varepsilon_{a} \sigma f\left(T_{a}, \omega_{\infty}\right)$, where $e$ is atmospheric radiance, $\sigma$ is the Stefan-Boltzmann constant, $T_{\mathrm{a}}$ is the average atmospheric temperature, and $\omega_{\infty}$ is total atmosphere water vapor. According to the previous analysis, cloud and DLR have a considerable influence on adjusting LER. As DLR is dominated by atmospheric temperature and humidity, we thus explore the influence of clouds, $T_{a}$, and RH on LER in different regions and seasons.

One of the primary aims of this study is to quantify the relationship between LER and its modulating factors in China. Correlation coefficients were thus calculated individually, both annually and for all seasons in the four climate regions, and results are shown in Figure 13.

In spring, summer, and autumn, the MCC metric shows statistically significant correlation coefficients $(r=-0.65,-0.71$, and -0.81 , respectively) associated with LER in region 1 (Figure 13(a)). The proportion of MCC in this region is high, and the seasonal distribution of cloud has a significant influence on seasonal change of LER. The HCC in autumn is significantly correlated $(r=-0.66)$ with LER. $\mathrm{RH}$ effects are mainly influenced in spring and autumn $(r=-0.61$ and -0.73 , respectively) and are related to water vapor transport characteristics in this region [46]. The negative correlations between MCC and LER in this region indicate that more MCC occurs in seasons when LER is weaker. The formation of cloud is closely related to humidity conditions, and the influence of RH is also significant. For region 2 (Figure 13(b)), HCC shows a high frequency, particularly in summer and autumn, and LER has significantly high correlations with HCC $(r=-0.61$ and -0.56 , respectively), whereas correlations in spring and winter are -0.57 . Humidity in this region is significant in spring and summer $(r=0.70$ and -0.62 , respectively). In contrast to region 1 , changes in spring and winter $T_{a}$ in this region have significant effects on LER $(r=0.62$ and 0.71 , respectively), which is considered to be related to the thermal effect of this region (as it is at a relatively high elevation). In most areas of region 3 (Figure 13(c)), water vapor is relatively abundant. The $\mathrm{RH}$ metric shows statistically significant correlation coefficients in spring, autumn, and winter $(r=-0.69,-0.84$, and -0.89 , respectively). In addition, LCC in winter and MCC in autumn are highly significant ( $r=-0.75$ and -0.76 , respectively), but $\mathrm{RH}$ is the foremost modulating factor in this region. For region 4 (Figure 13(d)), RH is also the main modulating factor, and it shows highly significant correlations in spring, summer, and autumn $(r=-0.55,-0.88$, and -0.83 , respectively). In autumn, MCC and $T_{a}$ have a higher correlation $(r=-0.74$ and 0.5 , respectively). Based on these phenomena, $T_{a}$ and LCC are considered to have no significant correlation with LER. The flux of moisture and sensible heat can be adjusted by ULR by poleward propagating Rossby waves, which increases total column water and temperature [47]. Atmospheric warming is often accompanied by surface warming, and the increase in $T_{a}$ and surface temperature lead to an increase in both DLR and ULR, thereby weakening the influence on LER. The effect of LCC on LER is reduced by its feedback to increasing temperature in the Earth-atmosphere system [48]. 

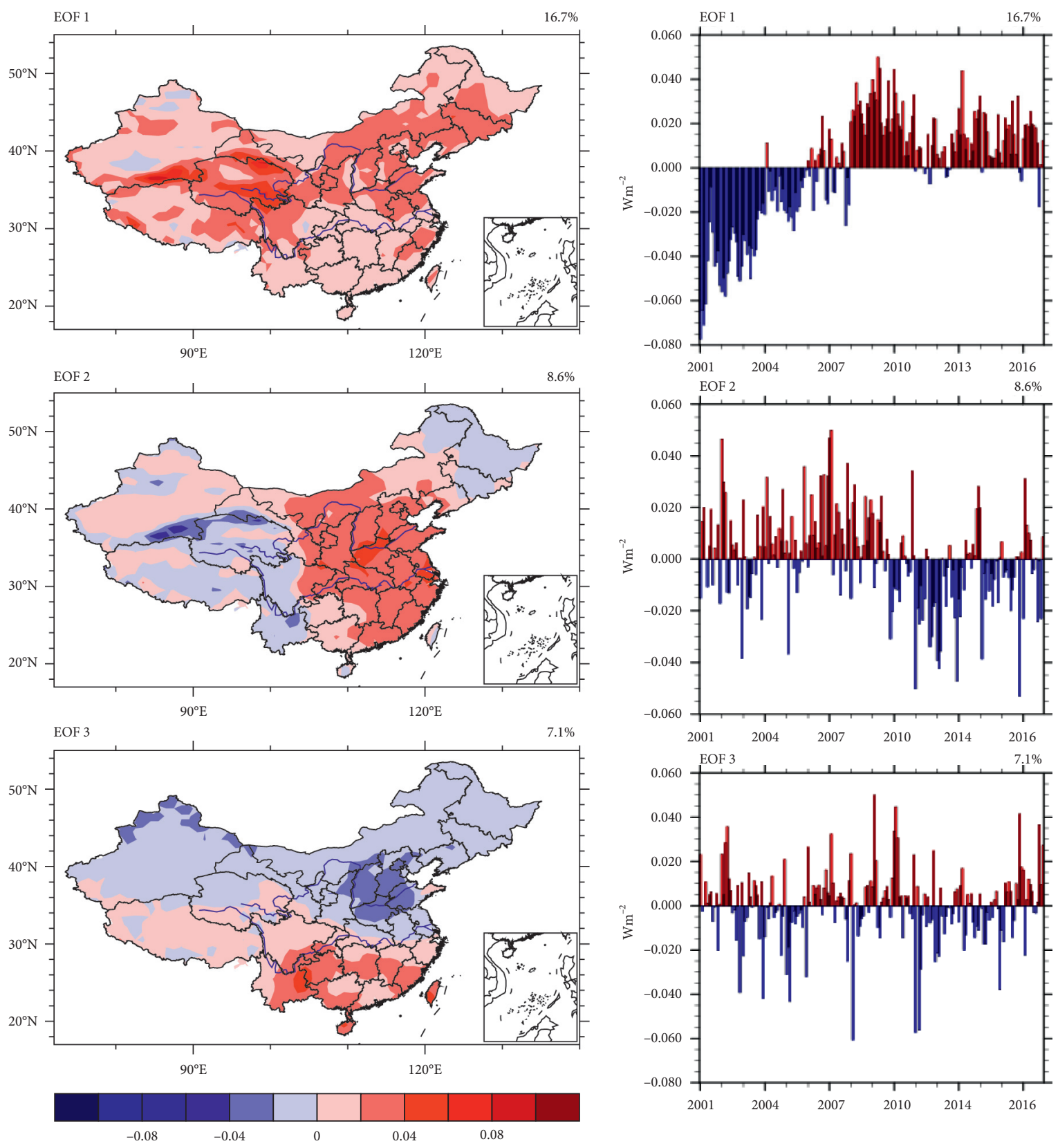

(a)

(b)

FIGURE 11: First three EOF modes of differences in LER in all-sky and clear-sky weather conditions (unit: Wm ${ }^{-2}$ ) in China: (a) spatial distribution of EOF modes and (b) corresponding time coefficient.

It is important to note that there is a lack of correlation between mean annual and seasonal LER and modulating factors in some regions (such as the mean annual results in region 2), which means they are coefficient predictors. Therefore, modulating factors were combined to evaluate LER when using the multiple linear regression method.

The goodness of fit coefficients (in Table 1) are significantly higher than individual goodness of fit coefficients.
In all four climate regions, $R^{2}$ is significant and most obvious in region 4 . The characteristics of these coefficients indicate that clouds, $T_{a}$, and $\mathrm{RH}$ can be combined to better explain the variability of all-sky LER in China than using individual metrics. However, the modulating factors related to seasonal and regional characteristics should be considered together when regulating LER values. 


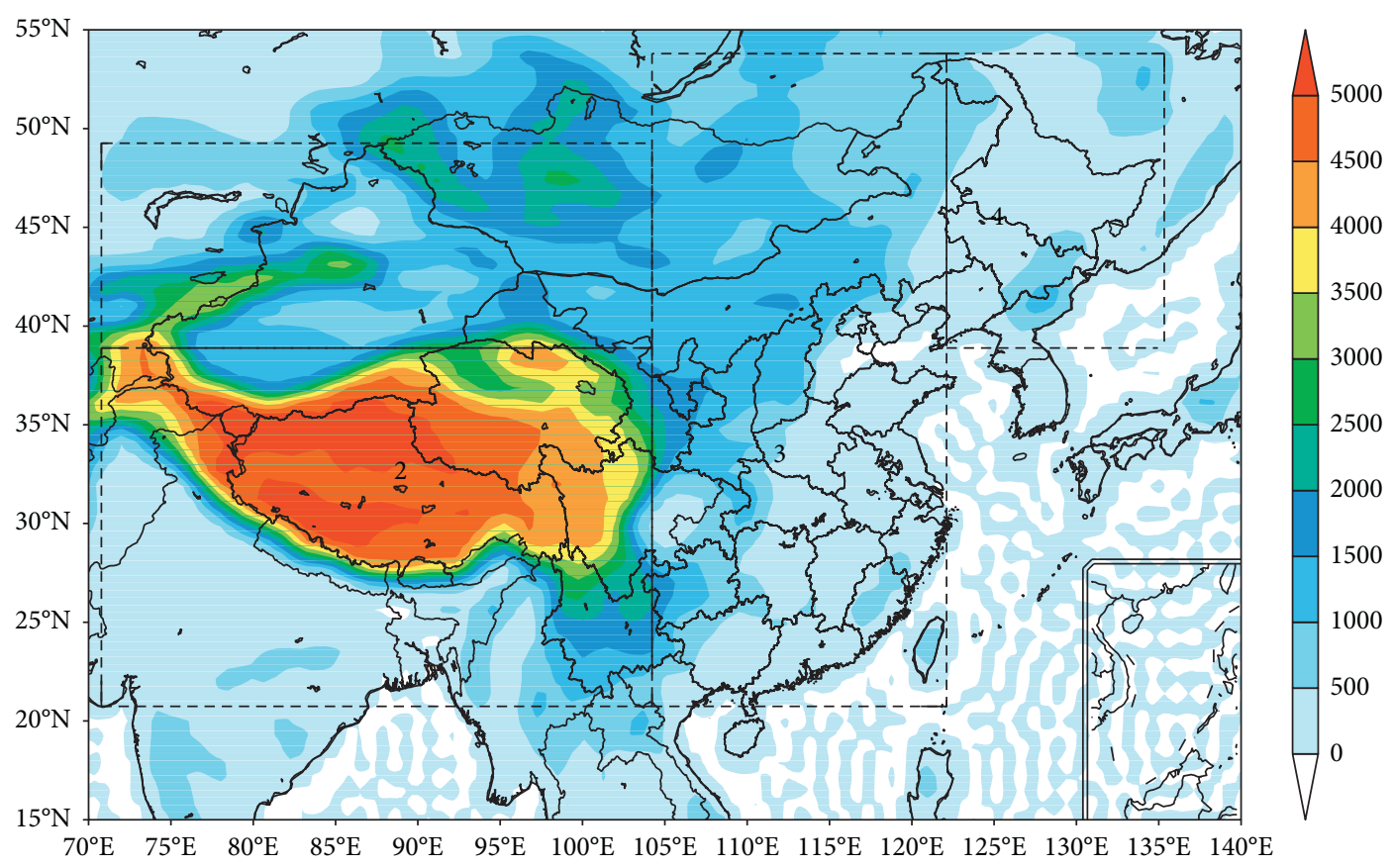

Figure 12: Topographic map of China (unit: $\mathrm{m}$ ) and four climatic regions. Region 1 is $38^{\circ} \mathrm{N}-49^{\circ} \mathrm{N}, 70^{\circ} \mathrm{E}-104^{\circ} \mathrm{E}$; region 2 is $25^{\circ} \mathrm{N}-40^{\circ} \mathrm{N}$, $70^{\circ} \mathrm{E}-104^{\circ} \mathrm{E}$; region 3 is $20^{\circ} \mathrm{N}-45^{\circ} \mathrm{N}, 104^{\circ} \mathrm{E}-122^{\circ} \mathrm{E}$; and region 4 is $40^{\circ} \mathrm{N}-50^{\circ} \mathrm{N}, 122^{\circ} \mathrm{E}-132^{\circ} \mathrm{E}$.

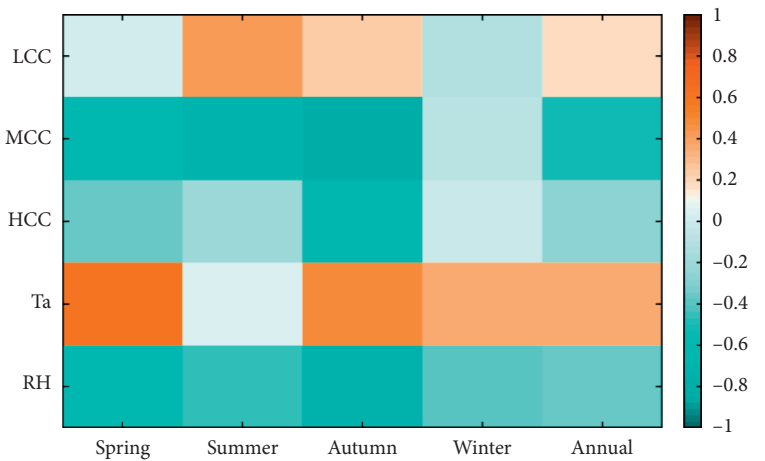

(a)

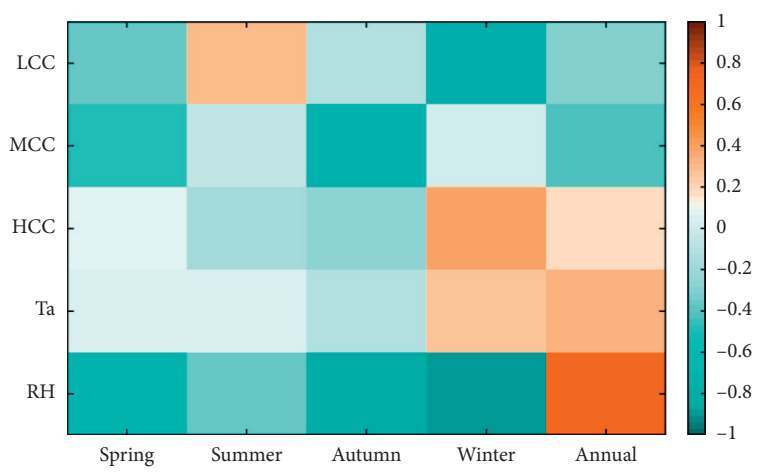

(c)

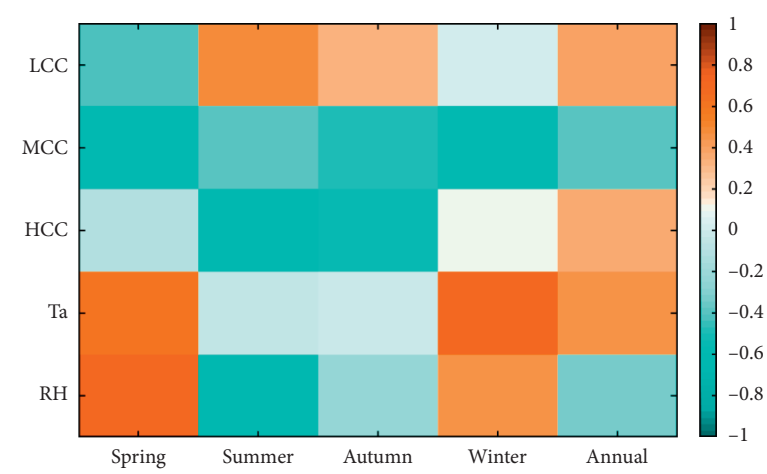

(b)

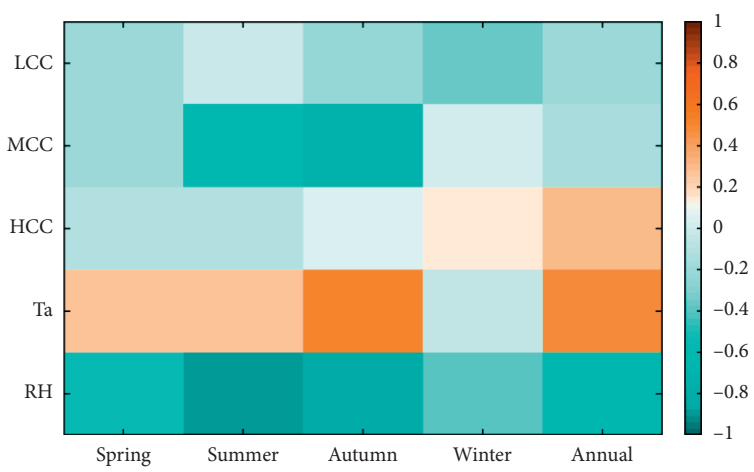

(d)

Figure 13: Correlation coefficients between all-sky LER and HCC, MCC, LCC, $T_{a}$, and RH in different regions and seasons during the period 2001-2016. (a) Region 1. (b) Region 2. (c) Region 3. (d) Region 4 . The absolute value above 0.49 is proven at a $95 \%$ significance level. 
TABLE 1: Correlation coefficients for multiple linear regressions conducted between annual and seasonal all-sky LER $\left(\mathrm{W} \mathrm{m}^{-2}\right)$ and cloud (\%), $\mathrm{Ta}\left({ }^{\circ} \mathrm{C}\right)$, and RH (\%) in four climatic regions. The asterisk means correlations significant at the $95 \%$ significance level.

\begin{tabular}{|c|c|c|c|c|c|}
\hline & Spring & Summer & Autumn & Winter & Annual \\
\hline Region 1 & $0.76^{*}$ & $0.82^{*}$ & $0.88^{*}$ & $0.62^{*}$ & $0.71^{*}$ \\
\hline Region 2 & $0.79^{*}$ & $0.79^{*}$ & $0.72^{*}$ & $0.82^{*}$ & $0.77^{*}$ \\
\hline Region 3 & $0.73^{*}$ & $0.66^{*}$ & $0.94^{*}$ & $0.93^{*}$ & $0.74^{*}$ \\
\hline Region 4 & $0.62^{*}$ & $0.92^{*}$ & $0.93^{*}$ & $0.70^{*}$ & $0.80^{*}$ \\
\hline
\end{tabular}

\section{Conclusion and Discussion}

LER is modulated by many factors, including cloud cover, surface elevation, temperature, and humidity, and this study aimed to investigate the influence of these factors. CERES-observed ULR and DLR data were used to conduct an assessment of LER in China during 2001-2016, and two schemes were included: all-sky and clear-sky conditions. The following primary conclusions can be made.

This study explored both all-sky and clear-sky LER, and results show that they both exhibit larger intensities in northwest China and a decreasing trend in their spatial distribution from northwest to southeast. The mean value of LER under clear-sky conditions is about $20-30 \mathrm{Wm}^{-2}$ higher than that in all-sky conditions; these results are consistent with those of a previous study [13].

For different seasons, LER under two different weather conditions has the largest value in spring, followed by summer, autumn, and then winter. ULR rapidly increases with an increase in surface temperature, and this then enhances LER. There are obvious differences between clear-sky LER in northwest China and all-sky LER; this is related to the increased surface albedo from snow cover. In summer, under the influence of abundant water vapor, increasing DLR leads to a reduction in LER. In autumn, less cloud cover enables more solar radiation to reach the surface and more heat to be absorbed; ULR and DLR thus increase simultaneously, and there are little differences between the values of LER in autumn and summer. However, in winter, ULR drops rapidly with the decreasing temperature and LER decreases accordingly. Although there are seasonal variations in spatial distributions, annual variations are quite similar.

Annual and seasonal variations of LER in China show a consistent and significant downward trend after 2007. There was a significant decrease in LER under two weather conditions in northwest China, eastern Tibetan Plateau, and southeast and northeast China. In addition, decreases in LER are more pronounced in spring with clear-sky conditions.

LER increases with an increase in ULR and decreases with an increase in DLR. The regression results indicate that LER is more sensitive to the change of DLR. Previous study also indicated that ULR affects more net shortwave flux, which leads to low correlation between LER and ULR [3]. Meanwhile, the cloud changes are crucial for LER. The difference of all-sky and clear-sky LER is discussed by applying the EOF analysis. The first pattern is characterized by more obvious distinction of different LER over China and the corresponding time series displays distinct negative-topositive phase shift after 2007. The second pattern depicts a multitronic anomaly pattern with positive anomalies centered in northeast China and Tibetan Plateau and negative signs in middle-south and northwest China. Besides, the temporal coefficients show a sudden decrease in 2009, implying this pattern is more obvious since then. The third mode shows a dipole pattern with anomalies of opposite signs between north and south China. The land cover, climate type, and surface elevation can effectively influence the LER [49]. Thus, we divided four climate regions to further analyze the seasonal and regional modulating factors of LER.

Regions 3 and 4 are areas with higher moisture than region 1 and 2, and LER is negatively correlated with RH in these regions. The moisture flux in these regions can increase the total column water and temperature and influence radiative processes $[47,50]$. However, higher negative correlations with cloud occur in regions 1 and 2, where cloud types have obviously different effects. The frequency of MCC occurrence is higher in region 1, and there is a significant negative correlation with LER. For region 2, the higher occurrence of HCC dominates negative correlations in summer and autumn, and MCC dominates in spring and winter. Furthermore, a positive correlation with $T_{a}$ is only seen in region 2 in spring and summer. Results of multiple linear regressions confirm the importance of these different metrics on LER in China; in particular, $R^{2}$ reaches 0.80 in region 4 .

In summary, this paper investigates the climate characteristics of LER under two types of weather conditions in China and their modulating factors. The results presented in this paper can be used as a reference for diagnosing the impact of future climate change on the Earth-atmosphere system radiation budget. It is considered that more attention should be directed to longwave fluxes in regions of high humidity, as recent warming and the occurrence of saturation and high cloud cover are modulated by this $[50,51]$. This paper shows that conducting a quantitative evaluation of the effects of climate modulating factors on long-wave radiation using satellite data is useful for improving calculations of radiative processes and can be used to predict and understand future climate change. In future work, we aim to evaluate each component of the radiation budget under different weather conditions.

\section{Conflicts of Interest}

The authors declare that they have no conflicts of interest. 


\section{Acknowledgments}

This study was supported by the National Key R\&D Program of China (2016YFA0601702). This study was also funded by "the Priority Academic Program Development of Jiangsu Higher Education Institutions" (PAPD).

\section{References}

[1] R. Knutti, T. F. Stocker, F. Joos, and G.-K. Plattner, "Constraints on radiative forcing and future climate change from observations and climate model ensembles," Nature, vol. 416, no. 6882, pp. 719-723, 2002.

[2] G. L. Smith, A. C. Wilber, S. K. Gupta, and P. W Stackhouse, "Surface radiation budget and climate classification," Journal of Climate, vol. 15, no. 10, pp. 1175-1188, 2002.

[3] P. E. Mlynczak, G. L. Smith, A. C. Wilber, and P. W. Stackhouse, "Annual cycle of surface longwave radiation," The Journal of Applied Meteorology and Climatology, vol. 50, no. 6, pp. 1212-1224, 2011.

[4] B. Tang and Z.-L. Li, "Estimation of instantaneous net surface longwave radiation from MODIS cloud-free data," Remote Sensing of Environment, vol. 112, no. 9, pp. 3482-3492, 2008.

[5] J. D. Haigh, "Radiative forcing of climate change," Weather, vol. 57, no. 8, pp. 278-283, 2002.

[6] H. K. Cho, J. Kim, Y. Jung, Y. G. Lee, and B. Y. Lee, "Recent changes in downward longwave radiation at King Sejong station, Antarctica," Journal of Climate, vol. 21, no. 22, pp. 5764-5776, 2008.

[7] R. P. Allan, "Evaluation of simulated clear-sky longwave radiation using ground-based observations," Journal of Climate, vol. 13, no. 11, pp. 1951-1964, 2000.

[8] M. Jansen, "Intergovernmental Panel on Climate Change (IPCC)," Encyclopedia of Energy Natural Resource \& Environmental Economics, vol. 26, no. 2, pp. 48-56, 2013.

[9] J. E. Harries, H. E. Brindley, P. J. Sagoo, and R. J. Bantges, "Increases in greenhouse forcing inferred from the outgoing longwave radiation spectra of the earth in 1970 and 1997," Nature, vol. 410, no. 6826, pp. 355-357, 2001.

[10] R. Henriquez and D. C. Nonhebel, "Testing longwave radiation parameterizations under clear and overcast skies at Storglaciären. Sweden," The Cryosphere, vol. 3, no. 1, pp. 75-84, 2009.

[11] I. Rangwala and J. R. Miller, "Climate change in mountains: a review of elevation-dependent warming and its possible causes," Climatic Change, vol. 114, no. 3-4, pp. 527-547, 2012.

[12] A. Slingo and M. J. Webb, "The spectral signature of global warming," Quarterly Journal of the Royal Meteorological Society, vol. 123, no. 538, pp. 293-307, 1997.

[13] H. Yu, J. Zhang, and H. Bai, "The variation of effective radiation in Qinghai-Tibetan Plateau based on the CERES satellite data," Plateau Meteorology, vol. 37, no. 1, pp. 106-122, 2018.

[14] W. Wang and S. Liang, "A method for estimating clear-sky instantaneous land-surface longwave radiation with GOES sounder and GOES-R ABI data," IEEE Geoscience and Remote Sensing Letters, vol. 7, no. 4, pp. 708-712, 2010.

[15] G. L. Ji, L. Lu, and J. Zou, "The seasonal variation of surface radiation energy budget over the Nothern Tibetan Plateau," Acta Energiae Solaris Sinica, vol. 16, no. 4, pp. 340-346, 1995.

[16] G. Bisht and R. L. Bras, "Estimation of net radiation from the MODIS data under all sky conditions: southern great plains case study," Remote Sensing of Environment, vol. 114, no. 7, pp. 1522-1534, 2010.

[17] P. M. Amatya, Y. Ma, C. Han, B. Wang, and L. P. Devkota, "Estimation of net radiation flux distribution on the southern slopes of the central Himalayas using MODIS data," Atmospheric Research, vol. 154, pp. 146-154, 2015.

[18] K. Nishida, R. R. Nemani, S. W. Running, and J. M. Glassy, "An operational remote sensing algorithm of land surface evaporation," Journal of Geophysical Research Atmospheres, vol. 108, no. D9, pp. 146-154, 2003.

[19] B. S. Barrett and S. Hameed, "Seasonal variability in precipitation in central and Southern Chile: modulation by the South Pacific high," Journal of Climate, vol. 30, no. 1, pp. 55-69, 2017.

[20] E. Hurtado and J. A. Sobrino, "Daily net radiation estimated from air temperature and NOAA-AVHRR data: a case study for the Iberian Peninsula," International Journal of Remote Sensing, vol. 22, no. 8, pp. 1521-1533, 2001.

[21] J. M. Jacobs, D. A. Myers, M. C. Anderson, and G. R. Diak, "GOES surface insolation to estimate wetlands evapotranspiration," Journal of Hydrology, vol. 266, no. 1-2, pp. 53-65, 2002.

[22] S. L. Carman, J. E. Cooper, J. Miller, E. F. Harrison, and B. R. Barkstrom, "Clouds and the earth's radiant energy system (CERES)," Bulletin of the American Meteorological Society, vol. 77, pp. 853-868, 1992.

[23] R. B. Lee, B. R. Barkstrom, S. L. Carman et al., "Clouds and the earth's radiant energy system (CERES) experiment, earth observing system (EOS) instrument, and calibrations," in Proceedings of the Optical Engineering and Photonics in Aerospace Sensing, vol. 1939, pp. 61-71, Orlando, FL, USA, August 1993.

[24] N. G. Loeb, N. Manalo-Smith, S. Kato et al., "Angular distribution models for top-of-atmosphere radiative flux estimation from the clouds and the earth's radiant energy system instrument on the tropical rainfall measuring mission satellite. Part I: methodology," The Journal of Applied Meteorology and Climatology, vol. 42, no. 2, pp. 240-265, 2003.

[25] D. R. Doelling, N. G. Leob, D. F. Keyes et al., "Geostationary enhanced temporal interpolation for CERES flux products," Journal of Atmospheric and Oceanic Technology, vol. 30, no. 6, pp. 1072-1090, 2013.

[26] E. Raschke, S. Bakan, and S. Kinne, "An assessment of radiation budget data provided by the ISCCP and GEWEXSRB," Geophysical Research Letters, vol. 33, no. 7, pp. 359-377, 2006.

[27] S. Gui, S. Liang, and L. Li, "Evaluation of satellite-estimated surface longwave radiation using ground-based observations," Journal of Geophysical Research Atmospheres, vol. 115, no. D18, pp. 1-14, 2010.

[28] N. Feng and S. A. Christopher, "Satellite and surface-based remote sensing of Southeast Asian aerosols and their radiative effects," Atmospheric Research, vol. 122, pp. 544-554, 2013.

[29] G. L. Smith, K. J. Priestley, N. G. Loeb et al., "Clouds and earth radiant energy system (CERES), a review: past, present and future," Advances in Space Research, vol. 48, no. 2, pp. 254263, 2011.

[30] C. M. Naud, I. Rangwala, M. Xu, and J. R. Miller, “A satellite view of the radiative impact of clouds on surface downward fluxes in the Tibetan Plateau," The Journal of Applied Meteorology and Climatology, vol. 54, no. 2, pp. 479-493, 2015.

[31] X. Dong, M. Patrick, B. Xi, S.-M. Sunny, and C. Yan, "Comparison of CERES-MODIS stratus cloud properties with ground-based measurements at the DOE ARM southern great 
plains site," Journal of Geophysical Research Atmospheres, vol. 113, no. D3, pp. 1-17, 2008.

[32] M. Sun and R. D. Cess, "Improvements in cloud identification over snow/ice surfaces from ERBE to CERES," Geophysical Research Letters, vol. 32, no. 5, pp. 373-383, 2005.

[33] D. P. Dee, S. M. Uppala, A. J. Simmons et al., "The ERAInterim reanalysis: configuration and performance of the data assimilation system," Quarterly Journal of the Royal Meteorological Society, vol. 137, no. 656, pp. 553-597, 2011.

[34] P. A. Mooney, F. J. Mulligan, and R. Fealy, "Comparison of ERA-40, ERA-Interim and NCEP/NCAR reanalysis data with observed surface air temperatures over Ireland," International Journal of Climatology, vol. 31, no. 4, pp. 545-557, 2011.

[35] P. H. Ramsey, "Statistical methods in the atmospheric sciences," Technometrics, vol. 38, no. 4, p. 402, 1996.

[36] Y. Ding and Z. Jiang, "The lack fidelity of EOFs expansion over heterogeneous network and its revised scheme," Acta Meteorologica Sinica, vol. 53, no. 2, pp. 247-253, 1995.

[37] D. S. Wilks, Statistical Methods in the Atmospheric Sciences International Geophysics Series, V. 91, Academic Press, Cambridge, MA, USA, 2nd edition, 2006.

[38] G. R. North, T. L. Bell, R. F. Cahalan, and F. J. Moeng, "Sampling errors in the estimation of empirical orthogonal functions," Monthly Weather Review, vol. 110, no. 7, pp. 699-706, 1982.

[39] L. Gao, K. Schulz, and M. Bernhardt, "Statistical downscaling of ERA-interim forecast precipitation data in complex terrain using LASSO algorithm," Advances in Meteorology, vol. 2014, Article ID 472741, 16 pages, 2014.

[40] J. Bernhardt and J. Kim, "Simulation of surface radiation balance on the Tibetan Plateau," Geophysical Research Letters, vol. 35, no. 8, pp. 813-826, 2008.

[41] H. Flohn and R. Elmar Reiter, Contributions to a Meteorology of the Tibetan Highlands, Corolado State University, Fort Collins, CO, USA, 1968.

[42] W. Cai, X. Xu, and J. Sun, “An investigation into the surface energy balance on the southeast edge of the Tibetan Plateau and the cloud's impact," Acta Meteorologica Sinica, vol. 70, pp. 837-846, 2012.

[43] J. Huang, Y. Wang, T. Wang, and Y. I. Yuhong, "Dusty cloud radiative forcing derived from satellite data for middle latitude regions of East Asia," Progress in Natural Science, vol. 16, no. 10, pp. 1084-1089, 2006.

[44] J. Zhou, J. Wen, X. Wang, D. Jia, and J. Chen, “Analysis of the Qinghai Xizang Plateau monsoon evolution and its correlation with soil moisture," Plateau Meteorology, vol. 36, no. 1, pp. $45-56,2017$.

[45] A. Duan and G. Wu, "Change of cloud amount and the climate warming on the Tibetan Plateau," Geophysical Research Letters, vol. 33, no. 22, pp. 217-234, 2006.

[46] N. Wei, Y. F. Gong, X. Sun, and J. G. Fang, "Variation of precipitation and water vapor transport over the Northwest China from 1959 to 2005," Journal of Desert Research, vol. 30, no. 6, pp. 1450-1457, 2010.

[47] T. Gong, S. Feldstein, and S. Lee, "The role of downward infrared radiation in the recent arctic winter warming trend," Journal of Climate, vol. 30, no. 16, pp. 4937-4949, 2017.

[48] V. S. Komarov, G. G. Matvienko, S. N. Ilyin, and N. Y. Lomakina, "The effect of the modern changes in the lowlevel stratiform clouds on the temperature regime of surface atmospheric layer in Siberia," Atmospheric and Oceanic Optics, vol. 29, no. 1, pp. 79-83, 2016.

[49] R. P. Allan, "Examination of relationships between clear-sky longwave radiation and aspects of the atmospheric hydrological cycle in climate models, reanalyses, and observations," Journal of Climate, vol. 22, no. 11, pp. 3127-3145, 2009.

[50] X. Ao, C. S. B. Grimmond, D. Liu et al., "Radiation fluxes in a business district of Shanghai, China," The Journal of Applied Meteorology and Climatology, vol. 55, no. 11, pp. 2451-2468, 2016.

[51] J. S. Wright, A. Sobel, and J. Galewsky, "Diagnosis of zonal mean relative humidity changes in a warmer climate," Journal of Climate, vol. 23, no. 17, pp. 4556-4569, 2010. 